\title{
A Snapshot of Reading, Searching, and Browsing Preferences of Tertiary Students
}

\author{
Nicholas Vanderschantz \\ Department of Computer Science \\ The University of Waikato \\ New Zealand \\ vtwoz@waikato.ac.nz
}

\author{
Claire Timpany \\ Department of Computer Science \\ The University of Waikato \\ New Zealand \\ ctimpany@waikato.ac.nz
}

\author{
Chun Feng \\ Department of Computer Science \\ The University of Waikato \\ New Zealand \\ cf37@students.waikato.ac.nz
}

\begin{abstract}
Unanswered questions remain regarding how to design search result pages in library catalogues that offer effective library seeking experiences for users - especially those designed for small screen mobile devices. This paper reports a snapshot interview of the user habits and preferences of tertiary library patrons during book searching and browsing and provides recommendations for library catalogue design and further research.
\end{abstract}

Book search, Digital library use, Library catalogue design, Mobile interface design

\section{INTRODUCTION}

Searching and browsing for printed books and eBooks using a library catalogue is now frequently conducted both within a physical library as well as outside that library. Recent technology innovations have provided an increase in availability of internet connected mobile devices to tertiary students and evidence (i.e. Hinze et al., 2017) shows that tertiary students are using mobile apps for academic purposes. This coupled with the common-place use of OPAC library systems for university and public libraries supports the need to investigate how tertiary students are searching, browsing for, and using books during their educational pursuits.

The design of library interfaces - specifically the design of library search results pages - will impact search success as well as user preference. This paper discusses our investigation into the use of library catalogue interfaces by tertiary students. We report a short interview that was conducted with students at two universities in NZ and China as a preface to a user interface observation study that will be reported elsewhere. The findings presented in this paper provide a snapshot of the library catalogue searching and browsing habits of tertiary students and preferences for the design of library catalogue interfaces for mobile devices.

We structure the paper as follows: Section 2 details related work on the display of book search results for searching and browsing. Section 3 and Section 4 present our interview study method and results. Sections 5 and Section 6 proposes future mobile interface design investigations for library catalogues designed for mobile devices.

\section{RELATED WORK}

Vemuri, Torres, Fox, Fan \& Shen (2006) identify that browsing and searching are fundamentally different activities, both fulfilling distinct but important roles in information search tasks. Central to our research into library catalogues is the correlation of searching and browsing and how digital catalogues support both of these related yet disparate techniques of book seeking.

Traditionally OPAC style interfaces are based on a card catalogue system for searching and the features of these interfaces are most suitable for users when a known book or item is being sought (Wells \& Richardson, 2014). However, when there are unknowns in the process then browsing options are required to increase searcher successes and may be best supported through a discovery system (Wells \& Richardson, 2014). Our research here focuses on the display of book search results and how related title browsing could be supported in library catalogue search.

Browsing the surrounding shelves for the books related to a specific search is a common technique used by information seekers in physical libraries (Bates, 1989). Morse (1971) defined browsing as a form of search that utilized serendipity and offered suggestions for how to increase chances of success when browsing. However, Cooper \& Prager (2000) suggest that electronic retrieval of information may hinder the serendipitous opportunities that may present themselves when browsing because of the filtering and relevance 
ranking that is undertaken by the search algorithms of digital collections. Participants in a study by McKay (2011) complained that online environments that they had experience with at the time did not afford opportunities for serendipitous book finding that physical library experiences had.

The search results page of an OPAC is crucial for information seekers because results pages provide lists of book options as well as bibliographic data. All of which impact decision making by users. We note that this is not a novel assertion, Shneiderman et al. (2000) recommend investigation into effective display of search results and Mi \& Weng (2008) identified considerations for displaying the results of a book search. However, we emphasise that this is of significance to users in providing one of the most obvious opportunities to afford browsing and serendipitous book finding. This is in contrast to the finding of Makri et al. (2006) who found participants in their study did not identify parallels between physical library browsing and their digital library browsing of results lists. We therefore propose that even in 2018 we need to further evaluate user's preferences for interfaces of book catalogues.

Display of search results in digital libraries and library catalogues have been investigated for some time. Text only results lists as well as text and visual information results lists are both found in digital library and library catalogue interfaces today. The required interface features for search result lists have seen investigation and recommendation for some time and provide guidance for requisite interface design investigation. Mi \& Weng (2008) identified the following 10 interface elements as necessary in a book results page: item availability, book covers, intuitive navigation between results lists and individual records, and the ability to browse related results by call number. Similarly, Noorhidawati \& Gibb (2008) found that their participants agreed that the book cover and access to the table of contents and index were important features when searching for ebooks in OPAC, but the book spine was seen to be less important. Similarly, Vanderschantz et al. (2015) investigated the design preferences of users on a personal eBook library catalogue on a mobile device. Their results showed that eBook selection could be influenced by visual display factors including; book cover, book-related information, metadata and book content. A common theme in the related work is the literal or metaphoric visual representation of physical features of books and library stacks in interface design for OPAC.

\section{METHOD}

An interview was conducted in 2017 to gain an overview of the reading and searching habits of tertiary students before conducting a more detailed observation task. Only the interview results are reported in this paper, no further detail of the observation task that followed the interviews will be reported.

The guided interview was conducted by a single researcher at one university in New Zealand and one university in China. The researcher recorded field notes of each interview and manual analysis was conducted post interview.

Interviews were typically conducted inside or within the immediate vicinity of each university's library. Both libraries contained printed and digital documents in both English and Chinese, amongst other languages. Participants at the NZ university typically undertook their studies in English, while participants from the Chinese university might be taught in either English or Chinese.

\subsection{Interview questions}

The interview questions were designed to require limited time of the participant and therefore no probes were developed for the questions asked. The small question set and the necessity to ensure limited participant time was to allow participation in an observed task using library interfaces following the interview which is reported elsewhere.

We asked a total of eleven questions, including two pre-screening questions and nine questions that were designed to gather demographic, reading habit, and preference results relating to library and library catalogue use.

The researcher was fluent in both English and Chinese and was able to conduct interviews at both universities in either English or Chinese depending on the participants preference for answering the questions. Ethical consent and information was made available to all participants in both English and Chinese.

\subsection{Participants}

75 participants ( 37 male and 38 female) agreed to take part in the study, 60 at the NZ university and 15 at the university in China. The participants' areas of study ranged the disciplines of the two universities at which the studies took place.

We did not collect ethnicity information from participants, though we did seek educational language preference from all participants. 65 participants reported a preference for studying in English, while 10 reported a preference for studying in Chinese. All 10 of the participants who preferred to study in Chinese were participants who were studying at the university in China.

\subsubsection{Participant recruitment screening}

Before beginning the study, participants were asked two pre-study questions to ascertain if they 
had experience reading and searching on a digital device. It was an intention of this study to include only participants who were familiar with reading and searching on a digital device and therefore participants who answered 'no' to one of these questions were thanked by the researcher but did not continue with the study. All 75 participants whose results we discuss in this paper stated that they had read and searched for reading material for educational purposes on a digital device.

\section{RESULTS}

The results that we report here provide a snapshot of the reading and library searching habits of our participants.

\subsection{Reading habits}

Participants were asked how often they read digital information in an educational or academic context. 31 participants reported reading digital text "almost every day". 25 participants stated that they read digital information once a week. Only 19 participants said they would read digital information once a month. As was expected due to our sampling procedure no participants reported never having read digitally. The researcher did not stipulate what reading digital information involved.

\subsection{Library browsing habits}

Participants were asked how often they browse for books in a physical library. 40 participants responded to this question by stating that they browsed a physical library once a month. 21 participants browsed books in a physical library once a week. Only 11 of the participants did this almost every day. Interestingly, as this study recruited library users, three (3) participants reported that they never browse the library shelves when searching for a physical book to borrow.

\subsection{Library borrowing habits}

Participants were also asked how often they borrow books from a physical library. The most common frequency for borrowing books was once a month, with 42 participants. Followed by 21 participants who get books out of a physical library once a week. A surprisingly high number, seven participants, stated that they borrowed books from the library almost every day. No probe was developed for this question before commencement of the study which did not allow for seeking deeper insight into this frequency of borrowing. We can only hypothesize that this would only be during a certain stage of study for a student or academic that such frequent physical library use would be likely. Surprisingly, five participants claimed to have never borrowed a book from a library. Again, because we had not produced a probe for this question, we cannot be sure if this was interpreted by the participants to mean a tertiary library or if in fact those five participants had never borrowed a book from any library (be that public, school, or tertiary). With such small numbers, we did not attempt to correlate this result with a particular academic discipline.

\subsection{Digital devices for reading \& searching}

We asked participants what type of digital devices they prefer for digital reading and searching. When answering this question some participants chose to report more than one device resulting in 89 responses from 75 participants.

The majority of our participants $(52 / 75)$ said they would most often use a computer (desktop or laptop) when searching for books and for much of their digital reading. Only 12 participants described preferring iOS tablet devices, while 10 participants preferred iOS mobile phones. Slightly lower numbers described Android devices to iOS devices, eight reporting a preference for Android tablets, and seven reporting Android phones as their preferred library searching and digital reading device. Therefore, 17 participants reported a preference for smaller screen mobile phones and 20 for tablet sized devices for searching and reading compared to 52 participants preferring desktop and laptop computers. This suggests that a greater number of our participants currently prefer searching and reading on screens larger than are currently afforded by mobile devices. As with other questions, there was no follow up to discover if the types of reading differed between device types.

\subsection{Importance of related books}

Participants were asked if related books were important to them when they were using library catalogues. This question did probe respondents to tell the research about their answer. Almost all of the participants (74) thought related books were important in the library search interface. Only one participant did not think that related or similar books to the topic they were investigating was important to them. Participants rated related books as important to them in physical libraries and library catalogues. The reasons provided by participants were they would assist with finding a wider range of appropriate books and sources, not simply a single possible result; would provide insights into ways to alter a search query; and might identify ways to broaden a research topic area.

\subsection{Importance of physical book features}

Participants were asked if the book cover was important to them in the library search page and 
were asked to explain why. 72/75 participants described the book cover as important to them. Participants were also asked if the book spine was important in the library search page. 43 participants considered the book spine important in the library search interfaces while the remaining 32 participants thought spines were unimportant to them during digital search.

Reasons given by participants for the importance of book covers included; making the book that they searched easy to find on the shelf; assisting with a decision on relevance and whether to loan the book; additional information; and improving the aesthetics of the interface. Participants described the book spine as important because it could help them to find the particular book on the shelf; and thought it could give them clear information about the books available related to their search.

\section{DISCUSSION}

A central outcome of these interviews is a snapshot of tertiary student's library use in 2017. We have identified frequent use of physical library's, and physical library books and the importance of physical attributes of library shelves and books in interface design for library catalogues. These features of the physicality of books and reading coupled with participants preferences for searching library catalogues on computers over mobile devices suggests a need for continued research into the design of library search interfaces for academic use. We will compare our findings to the related work in the remainder of this section.

Our interviews showed high numbers of students still regularly use the physical library and physical library books. This continued high use of physical library books is of significance to libraries in light of the caution by McKay et al. (2015) who note that libraries are increasingly offering only eBooks for portions of their collections. Over half of the students we interviewed browsed for physical books from a library and reported borrowing books at least once a month. In this interview, we did not ask about the comparative frequency of our participants digital search and browsing for physical library books. Future work that compares search and browsing in digital and physical situations will help to identify if users still report similar concerns to those identified by McKay (2011).

Almost half of the participants reported reading digital information almost every day. This compares to the findings of Liu (2005) who found in their survey that $83 \%$ of participants reported that the amount of time they spent reading digital material was increasing compared to $67 \%$ of the same group reporting that the amount of time they spent reading print material was increasing. Interestingly, searching and reading digital material for educational purposes was typically preferred to be done on a desktop or laptop computer rather than a mobile device. Similarly, mobile library apps and search tools were also not reportedly used for academic purposes by respondents to the survey conducted by Hinze et al. (2017). Investigation is required to identify if this is because computers are the common tools used for information seeking or if students do not use mobile library apps due to shortcomings of interfaces on mobile devices.

It has been reported widely that book covers effect user selection in physical libraries (i.e. Reutzel \& Gali 1998; Hinze, McKay et al. 2012; Stelmaszewska \& Blandford 2004) and bookshops (Buchanan \& McKay 2011). When we consider the preferences of our participants for the display of information in a library search interface we see the importance of the book cover in the interface. This preference for inclusion of book covers that came out of our interviews reinforces the findings of McKay et al. (2012) who noted that the length of read time and tendency to abandon a book was influenced by inconsistencies and errors in the interface relating to metadata information as well as cover presentation. Similar to our finding here, Vanderschantz et al. (2015) reported that users preferred an interface that displayed both a book cover and supporting bibliographic information.

The spines of books are also shown to impact browsing, and book selection in physical library's and stands to reason to be an effective visual tool for searching related books, despite Noorhidawati \& Gibb (2008) finding that spines may not be considered as important in online library catalogues. Interestingly, slightly more participants in our study considered spines to be important to them in library search result interfaces than participants who did not consider spines important.

\section{CONCLUSION}

This interview study provided a snapshot of the information search habits of 75 participants across two universities in 2017. This paper explored interface and information presentation for library catalogues and digital libraries used by tertiary students. Given the increased mobile information access and use by students the findings of this early work should be of concern to the designers and developers of library catalogues and digital libraries. Our results provide three requirements for future investigation, 1) of why students don't commonly use mobile devices to search for reading material, 2) how best to design interfaces that support reading on mobile devices, 3) how features and affordances of physical libraries and physical books can be implemented in library catalogues. 


\section{REFERENCES}

Bates, M. J. (1989). The design of browsing and berrypicking techniques for the online search interface. Online review, 13(5):407-424.

Cooper, J.W. \& Prager, J.M. (2000). Antiserendipity: finding useless documents and similar documents, In Spragu, R.H. (Ed.), Proceedings of the 33rd Annual Hawaii International Conference on System Sciences, Maui, Hawaii, IEEE Computer Society, Piscataway, NJ.

Gaona-García, P. A., Martin-Moncunill, D., \& Montenegro-Marin, C. (2017). Trends and challenges of visual search interfaces in digital libraries and repositories. The Electronic Library, 35(1):69-98.

Hinze, A., McKay, D., Vanderschantz, N., Timpany, C., \& Cunningham, S. J. (2012). Book selection behavior in the physical library: Implications for ebook collections. In Proceedings of the 12th ACM/IEEE-CS joint conference on Digital Libraries, p.305-314. ACM, New York, NY.

Hinze, A., Vanderschantz, N., Timpany, C., Saravani, S-J., Cunningham, S. J., \& Wilkinson, C. (2017). Use of Mobile Apps for Teaching and Research-Implications for Digital Literacy. In Proceedings of the International Conference on Asian Digital Libraries. p.173-184. Springer, Berlin, Heidelberg.

Lawson, B. (2006). How designers think the design process demystified $\left(4^{\text {th }} \quad\right.$ ed. $)$. Elsevier/Architectural, Oxford; Burlington, MA.

Liu, Z. (2005). Reading behavior in the digital environment: Changes in reading behavior over the past ten years, Journal of Documentation, 61(6):700-712.

Makri, S., Blandford, A. , Gow, J. , Rimmer, J. , Warwick, C. and Buchanan, G. (2007), A library or just another information resource? A case study of users' mental models of traditional and digital libraries. J. Am. Soc. Inf. Sci., 58: 433445.

McKay, D. (2011). Gotta keep'em separated: why the single search box may not be right for libraries. In Proceedings of the 12th Annual Conference of the New Zealand Chapter of the ACM Special Interest Group on ComputerHuman Interaction (pp. 109-112). ACM.

McKay D., Buchanan G., Chang S. (2015) Tyranny of Distance: Understanding Academic Library Browsing by Refining the Neighbour Effect. In: Kapidakis S., Mazurek C., Werla M. (eds) Research and Advanced Technology for Digital Libraries. Lecture Notes in Computer Science, vol 9316. Springer, Cham
McKay, D., Hinze, A., Heese, R., Vanderschantz, N., Timpany, C., \& Cunningham, S. J. (2012). An exploration of ebook selection behavior in academic library collections. In International Conference on Theory and Practice of Digital Libraries p.13-24. Springer, Berlin, Heidelberg.

McKay, D., Buchanan, G., Vanderschantz, N., Timpany, C., Cunningham, S. J., \& Hinze, A. (2012). Judging a book by its cover: interface elements that affect reader selection of ebooks. In Proceedings of the 24th Australian ComputerHuman Interaction Conference. ACM, New York, NY, US.

Merčun, T. \& Žumer, M. (2008). New generation of catalogues for the new generation of users: $A$ comparison of six library catalogues, Program, 42(3):243-261.

Mi, J., \& Weng, C. (2008). Revitalizing the library OPAC: Interface, searching, and display challenges. Information Technology and Libraries, 27(1):5-22.

Morse, P.M. (1971). On browsing: the use of search theory in the search for information, Bulletin of the Operations Research Society of America, supplement, 19, p.1.

Noorhidwaati, A. \& Gibb, F. (2008) How Students Use E-books-Reading or Referring?, Malaysian Journal of Library and Information Science 13(2):1-14.

Olston, C. \& Chi, E. H. 2003. ScentTrails: Integrating browsing and searching on the Web. ACM Transactions on Computer-Human Interaction. 10(3):177-197.

Ross, C. S. (2000). Making choices: What readers say about choosing books to read for pleasure. The Acquisitions Librarian, 13(25):521.

Shneiderman, B., Feldman, D., Rose, A., \& Grau, X. F. (2000). Visualizing digital library search results with categorical and hierarchical axes. In Proceedings of the fifth ACM conference on Digital libraries (p.57-66). New York, NY: ACM.

Su, S. (2005). Desirable search features of webbased scholarly e-book systems, The Electronic Library, 23(1):64-71.

Vanderschantz, N., Timpany, C., and Hinze, A. (2015). Design exploration of ebook interfaces for personal digital libraries on tablet devices. In Proceedings of the 15th New Zealand Conference on Human-Computer Interaction, p.21-30. ACM.

Vasileiou, M., Hartley, R. \& Rowley, J. (2012). Choosing e-books: a perspective from academic libraries, Online Information Review, 36(1):21-39. 
Vemuri, N. S., Torres, R. D. S., Fox, E. A., Fan, W., \& Shen, R. (2006, June). Exploring digital libraries: integrating browsing, searching, and visualization. In Digital Libraries, 2006. JCDL'06. Proceedings of the 6th ACM/IEEE-CS Joint Conference on (p.1-10). IEEE.
Wells, D., \& Richardson, C. (2014). How do library clients use discovery systems. In LIANZA Conference (pp. 12-15).

Wiederhold, G. (1995). Digital libraries, value, and productivity. Communications of the ACM, 38(4): 85-96. 